\title{
Laterality: Right-Sided and Left-Sided Colon Cancer
}

\author{
Seong Kyu Baek \\ Department of Surgery, Keimyung University Donsan Medical Center, Keimyung University School of Medicine, Daegu, Korea
}

\section{See Article on Page 210-218}

Colorectal cancer (CRC) can be characterized by the location of the primary tumor being within the colon [1]. Right-sided colon cancer (RCC) is derived from the embryologic midgut, including the proximal two-thirds of the transverse colon, ascending colon, and cecum. Left-sided colon cancer (LCC) is derived from the embryologic hindgut, which includes the distal third of the transverse colon, splenic flexure, descending colon, sigmoid colon, and rectum. Differences in the microbiome, clinical characteristics, and chromosomal and molecular characteristics between the right-sided and the left-sided colon have been reported [2]. Over the past few years, the distinction between RCC and LCC has been brought into focus due to their having different outcomes, prognoses, and clinical responses to chemotherapy.

For metastatic CRC, clinical studies now provide strong evidence about the prognostic and the predictive value of the primary tumor's location $[3,4]$. A meta-analysis of clinical studies reporting overall survival (OS) data for patients with metastatic LCC and RCC revealed that those with RCC had poorer prognosis than those with LCC [5]. Data regarding the predictive value of laterality indicate that the primary tumor's location has a predictive effect for first- and second-line anti-epidermal growth factor receptor (anti-EGFR) treatment and for treatment in the chemo-refractory setting [6]. Although tumor location is not included within the European Society for Medical Oncology consensus guidelines for metastatic CRC, the National Comprehensive Cancer Network guidelines recommend the use of antiEGFR substances for the treatment of RAS wild-type LCC only [7]. In nonmetastatic CRC, patients with RCC tend to be older

Correspondence to: Seong Kyu Baek, M.D.

Department of Surgery, Keimyung University Donsan Medical Center, Keimyung University School of Medicine, 56 Dalseong-ro, Jung-gu, Daegu 41931, Korea

Tel: +82-53-250-8050, Fax: +82-53-250-7322

E-mail:sgbeak@dsmc.or.kr

(C) 2017 The Korean Society of Coloproctology

This is an open-access article distributed under the terms of the Creative Commons Attribution NonCommercial License (http://creativecommons.org/licenses/by-nc/4.0) which permits unrestricted noncommercial use, distribution, and reproduction in any medium, provided the original work is properly cited. and female, with tumors that are larger, at more advanced stages, and poorly differentiated, compared to patients with LCC $[8,9]$. However, these findings are based on studies that included all stages of the disease.

Currently, data on the prognoses for patients with nonmetastatic RCC and LCC are conflicting, and whether the tumor's location itself has a significant prognostic impact remains a matter for debate. Although most studies showed poorer survival for patients with primary tumors located on the right side, a study by Weiss et al. [10] demonstrated no difference between the 5-year OSs for patients with RCC and LCC after adjusting for multiple variables; instead, they found that the mortality in patients with stage II RCC was lower than it was in those with LCC (hazard ratio [HR], 0.92 ; $95 \%$ confidence interval $[\mathrm{CI}], 0.87-0.97 ; \mathrm{P}=0.001$ ). On the other hand, the mortality was higher in patients with stage III RCC (HR, 1.12; 95\% CI, 1.06-1.18; P < 0.001).

A population-based Surveillance, Epidemiology, and End Results (SEER) analysis of patients with nonmetastatic colon cancer provided evidence that the prognosis for patients with RCC was better regarding OS and cancer-specific survival (CSS). Subgroup analyses of patients with stages I and II colon cancer provided evidence that the prognosis for RCC was better in terms of OS (HR, 0.89 ; $95 \%$ CI, $0.84-0.94$ vs. HR, 0.85 ; 95\% CI, $0.81-0.89$ ) and CSS (HR, $0.71 ; 95 \% \mathrm{CI}, 0.64-0.79$ vs. HR, 0.75 ; $95 \% \mathrm{CI}, 0.70-0.80$ ). In the same analysis, patients with RCC and LCC showed similar prognoses for stage III cancer (OS: HR, 0.99 and 95\% CI: 0.951.03; CSS: HR, 1.04 and 95\% CI, 0.99-1.09) [11]. Another population-based SEER analysis of patients with stage II colon cancer did not reveal an association between laterality and OS [12].

Jung et al. [13] analyzed the clinicopathological differences between patients with RCC and LCC and evaluated the impact of the laterality of the primary tumor on recurrence and survival after a curative resection of nonmetastatic colon cancer. RCC demonstrated a female dominance and undifferentiated pathology more frequently. On comparing the 5-year disease-free survival and OS by pathologic stage, no differences between patients with RCC and LCC in stages I and II were observed. However, patients with stage III RCC showed significantly worse disease-free survival $(58 \%$ vs. $72.7 \%, \mathrm{P}=0.01)$ and $\mathrm{OS}(66.6 \%$ vs. $82.3 \%, \mathrm{P}=$ $0.0026)$ than patients with LCC did. This analysis addressed meaningful and important points. However, as the authors have 
revealed, because of the limitations of this study, the authors could not provide information about the genetic status of the tumor regarding DNA MMR status, as well as KRAS and BRAF status, which might be a possible clue to explaining the conflicting data.

In recent years, the interest in identifying the differences between patients with RCC and LCC has been increasing, as has the potential for using the primary tumor's location to improve the personalization of systemic treatments. Overall, the existing literature shows conflicting data regarding the prognoses for patients with RCC and LCC. The reasons for this remain unclear; however, clinicopathological and genetic factors, including tumor grade, tumor histology, DNA MMR status, KRAS and BRAF status, advanced stage, and laterality, may play a role. Till now, heterogeneity within the literature, including in the study designs, disease stages, and treatment informations, has been significant. Additional research is required to define the factors and tumor biology more clearly with regard to colon cancer laterality.

\section{CONFLICT OF INTEREST}

No potential conflict of interest relevant to this article was reported.

\section{REFERENCES}

1. Bufill JA. Colorectal cancer: evidence for distinct genetic categories based on proximal or distal tumor location. Ann Intern Med 1990;113:779-88.

2. Stintzing S, Tejpar S, Gibbs P, Thiebach L, Lenz HJ. Understanding the role of primary tumour localisation in colorectal cancer treatment and outcomes. Eur J Cancer 2017;84:69-80.

3. Nitsche U, Stögbauer F, Späth C, Haller B, Wilhelm D, Friess H, et al. Right sided colon cancer as a distinct histopathological subtype with reduced prognosis. Dig Surg 2016;33:157-63.

4. Venook AP, Niedzwiecki D, Innocenti F, Fruth B, Greene C, O'Neil $\mathrm{BH}$, et al. Impact of primary tumor $\left(1^{\circ}\right)$ location on overall surviv$\mathrm{al}(\mathrm{OS})$ and progression free survival (PFS) in patients (pts) with metastatic colorectal cancer (mCRC): analysis of CALGB/SWOG 80405 (Alliance). J Clin Oncol 2016;34(15 Suppl). Abstract No. 3504.

5. Petrelli F, Tomasello G, Borgonovo K, Ghidini M, Turati L, Dallera $\mathrm{P}$, et al. Prognostic survival associated with left-sided vs right-sided colon cancer: a systematic review and meta-analysis. JAMA Oncol 2016 Oct 27 [Epub]. https://doi.org/10.1001/jamaoncol.2016.4227.

6. Brulé SY, Jonker DJ, Karapetis CS, O'Callaghan CJ, Moore MJ, Wong $\mathrm{R}$, et al. Location of colon cancer (right-sided versus leftsided) as a prognostic factor and a predictor of benefit from cetuximab in NCIC CO.17. Eur J Cancer 2015;51:1405-14.

7. National Comprehensive Cancer Network (NCCN) clinical practice guidelines in oncology. Colon cancer [Internet]. Fort Wathington (PA): National Comprehensive Cancer Network; c2017 [cited 2017 Nov 10]. Available from: https://www.nccn.org/professionals/physician_gls/pdf/colon.pdf.

8. Nawa T, Kato J, Kawamoto H, Okada H, Yamamoto H, Kohno H, et al. Differences between right- and left-sided colon cancer in patient characteristics, cancer morphology and histology. J Gastroenterol Hepatol 2008;23:418-23.

9. Sinicrope FA, Shi Q, Smyrk TC, Thibodeau SN, Dienstmann R, Guinney J, et al. Molecular markers identify subtypes of stage III colon cancer associated with patient outcomes. Gastroenterology 2015;148:88-99.

10. Weiss JM, Pfau PR, O'Connor ES, King J, LoConte N, Kennedy G, et al. Mortality by stage for right- versus left-sided colon cancer: analysis of surveillance, epidemiology, and end results--Medicare data. J Clin Oncol 2011;29:4401-9.

11. Warschkow R, Sulz MC, Marti L, Tarantino I, Schmied BM, Cerny T, et al. Better survival in right-sided versus left-sided stage I - III colon cancer patients. BMC Cancer 2016;16:554.

12. Schrag D, Weng S, Brooks G, Meyerhardt JA, Venook AP. The relationship between primary tumor sidedness and prognosis in colorectal cancer. J Clin Oncol 2016;34(15 Suppl). Abstract No. 3505.

13. Jung MK, Shin US, Ki YJ, Kim YB, Moon SM, Sung SJ. Is the location of the tumor another prognostic factor for patients with colon cancer? Ann Coloproctol 2017;33:210-8. 